\title{
ELASTOGRAPHY: THE IMPACT OF THE USE OF THE TOOL FOR THE CHARACTERIZATION OF BREAST LESIONS
}

Valeska C. Andrade1, Henrique A. P. Pasqualette1, Paulo M. Soares-Pereira', Vânia R. M. Sondermann¹, Laila Feld ${ }^{1}$, Daniela Machado'

${ }^{1}$ Centro de Estudos e Pesquisa da Mulher - Rio de Janeiro (RJ), Brazil.

Objective: Elastography is a technology that evaluates the rigidity of tissues. The aim is to validate its use in combination with USM to improve the characterization of breast lesions, increasing the specificity of the method and, thus, targeting lesions more accurately for biopsy. Material and method: Four patients with lesions category 3, 4 and 5 BI-RADS ${ }^{\circledR}$, less than $2 \mathrm{~cm}$, with a mean age of 47 years, were evaluated with USM and elastography. The results were confronted with the histopathological, considered gold standard. The USM equipment was GE Logic 7 Expert, with strain elastography technology, and the resistance criterion described in the associated findings chapter of BI-RADS ${ }^{\circledR}$, soft or rigid was used. Results: 17 rigid and 13 soft ( 0 malignant) 3 - 4 nodules were found; 24 category $4 \mathrm{~A}$ - 5 rigid (5 benign) and 19 soft (19 benign); 27 category $4 \mathrm{~B}$ - 13 rigid ( 2 malignant and 11 benign) and 14 soft (12 benign and 2 malignant); 26 category $4 \mathrm{C}-20$ rigid (13 malignant and 7 benign) and 6 soft (5 benign and 1 malignant); and 10 category 5 - 8 rigid and 2 soft (10 malignant). Sensitivity 82\%, specificity 65\%, PPV 46\%, and VPN 90\%. Conclusion: Elastography is a tool that, despite being a dependent operator, can improve the characterization of breast lesions, making a more precise indication of procedures. Keywords: elastography, breast cancer, percutaneous breast biopsy. 